\title{
Paediatric left ventricular assist device and heart transplantation - a single centre experience
}

\author{
AN Mdladla (D) \\ Chief Intensivist and Associate Professor, Sefako Makgatho University and Cardiac Anaesthetist, Maboneng Heart Institute, South Africa \\ Corresponding author, email: nathimdladla@gmail.com
}

Keywords: paediatric end-stage heart failure, paediatric left ventricular assist device (LVAD), paediatric heart transplantation, LVAD complications

\section{Introduction}

The fate of children with end-stage heart failure requiring transplantation in South Africa still remains dismal in 2020 due to the scarcity of available donor hearts, shortage of requisite expertise and lack of funding. This situation is worst for the younger and smaller sized children who cannot make it into the adult programmes utilising hearts of smaller sized donors. The introduction of the left ventricular assist device programme into one of the private hospitals in Johannesburg, Gauteng, as a bridge to heart transplantation gave some of these children a fighting chance and a return to some semblance of function while awaiting a new heart. The challenges faced when setting up such a programme are immense, the procedure itself is arduous and the kids face multiple trials and tribulations during the waiting period until they receive a new heart.

\section{Methods}

This is a commentary based on personal author observations as an outsider and a cardiac anaesthetist in the programme, discussions with the team of surgeons and coordinators, interaction with family members and inputs from the staff involved with the care of the children. A number of key individuals were sent questions requesting key information or to share a historical perspective and opinions. The families of the kids were contacted through the transplant coordinators for permission to use the pictures and videos of the children at various stages of their journey.

\section{Discussion}

A well established renal transplant programme is a prerequisite before liver and heart transplant programmes are to be considered in any country. South Africa has had about three centres performing heart and lung transplants in three provinces for decades now. Paediatric renal transplantation is performed in about five centres, while paediatric liver transplantation is done in only two centres. Until 2015, paediatric heart transplants were done as part of an adult programme in bigger kids who were able to take small adult hearts, the fate of smaller children was and still is a palliative endeavour until demise, with varying levels of surgical and medical interventions.

There are numerous obstacles to paediatric heart transplantation in spite of the fact that South Africa has the historical advantage and prestige to have performed the first successful heart transplant in the world. The challenges include organ availability in this young population, the lack of clear guidelines around "brain death" certification (limiting the donor pool), curtailment of adult heart transplantation in the state sector, the reluctance of funders to fund new assist device technologies in the private sector, and to a degree the lack of expertise in paediatric ventricular assist device implantation in South Africa.

This changed somewhat in 2015 when a young South African paediatric cardiac surgeon who returned from Canada had the enthusiasm and goal to set up the first paediatric ventricular assist device (LVAD) and heart transplant programme in Johannesburg. This was no easy feat, the stumbling blocks were numerous and enormous, including the involvement of statutory bodies in certain situations where donors were refusing to cover life-sustaining devices. Eventually the first LVAD was implanted setting out a path for more devices and making the transplant programme a possibility. A lot of the children's lives have been changed by this, but sadly, for a whole lot more it was either too late or they just never had the opportunity to even be considered for transplantation for various reasons. Sadly the surgeon who started this exciting phase and impacted a lot of children and family lives has been poached back to Canada, leaving an immense void.

Receiving an LVAD is just the start, and this bridge to transplantation is filled with its own challenges. The surgery and immediate postoperative environment can be a rocky one. After hospital discharge, the continued threat and manifestation of recurrent infections and anticoagulation therapy management issues remain a course of major morbidity and hospitalseeking for these patients. After receiving the new heart and embarking on immunosuppressive therapy, a new management challenge ensues. For the younger children, the transition into 
teenagehood, with its own new set of competing interests and hormonal/medical changes poses new threats.

\section{Conclusion}

This presentation aims to share the hardships of setting up an LVAD and heart transplant programme in one private hospital in Johannesburg, and shed insights into the peri-operative management and the subsequent challenge in managing the interceding complications including nature's challenges as the children grow up. It also sets out to ask what the future looks like for the current children on LVADs and the ones recently diagnosed with end-stage heart failure with no immediate availability of left ventricular assist device as a bridge to transplantation?

\section{ORCID}

AN Mdladla (D https://orcid.org/0000-0001-6978-4382

\section{References}

1. Kinsley RH, Edwin F, Colsen PR, et al. Paediatric cardiac surgery for a continent The experience of the Walter Sisulu Paediatric Cardiac Centre for Africa. SA Heart. 2011;8:122-9. https://doi.org/10.24170/8-2-1907.

2. Malan M. Heart transplant: the story of Barnard and the ultimate in cardiac surgery. South Africa: Voortrekkerpers; 1968

3. Spearman CWN, McCulloch MI. Challenges for paediatric transplantation in Africa. Pediatr Transplant. 2014;8:668-674. https://doi.org/10.1111/petr.12333. 